\title{
Extractive recovery and valorisation of arsenic from contaminated soil through phytoremediation using Pteris cretica
}

\author{
Valentine C. Eze $^{1}$ and Adam P. Harvey ${ }^{1}$
}

${ }^{1}$ School of Engineering, Newcastle University, Newcastle upon Tyne, NE1 7RU, UK. Corresponding:Tel.: +44-191-208-5747; E-mail address: v.eze@ncl.ac.uk (Valentine C. Eze)

\section{Abstract}

Contamination of ground water and soil by arsenic poses serious environmental challenges globally. A possible solution to this problem is through phytoremediation using hyper-accumulating plants. This study investigates phytoremediation of soil containing $200 \pm 3 \mathrm{mg} \mathrm{kg}^{-1}$ of arsenic using Pteris cretica ferns, and the strategies for arsenic extraction from the ferns biomass and subsequent conversions to valuable arsenic products. The Pteris cretica ferns achieved maximum arsenic accumulations of 4427 \pm 79 to $4875 \pm 96 \mathrm{mg}$ of arsenic per $\mathrm{kg}$ dry biomass after 30 days. Extraction efficiencies of arsenic in the ferns fronds were $94.3 \pm 2.1 \%$ for ethanol-water $(1: 1 \mathrm{v} / \mathrm{v}), 81.5 \pm 3.2 \%$ for $1: 1(\mathrm{v} / \mathrm{v})$ methanolwater, and $70.8 \pm 2.9 \%$ for water alone. Molybdic acid process was used to recover $90.8 \pm 5.3 \%$ of the arsenic, and $95.1 \pm 4.6 \%$ of the phosphorus in the biomass extract. Quantitative precipitation of $\mathrm{Mg}_{3}\left(\mathrm{AsO}_{4}\right)_{2}$ and $\mathrm{Mg}_{3}\left(\mathrm{PO}_{4}\right)_{2}$ occurred on treatment of the aqueous solutions of arsenic and phosphorus after stripping at $\mathrm{pH}$ of $8-10$. The efficiencies of $\mathrm{Mg}_{3}\left(\mathrm{AsO}_{4}\right)_{2}$ and $\mathrm{Mg}_{3}\left(\mathrm{PO}_{4}\right)_{2}$ precipitation were $96 \pm$ $7.2 \%$ and $94 \pm 3.4 \%$, respectively. Arsenic nanoparticles produced from the recovered $\mathrm{Mg}_{3}\left(\mathrm{AsO}_{4}\right)_{2}$, using two-stage reduction process, had average particle diameters of $45.5 \pm 11.3 \mathrm{~nm}$. These nanoparticles are potentially valuable for medical applications, while the $\operatorname{Mg}_{3}\left(\mathrm{AsO}_{4}\right)_{2}$ could be converted to more valuable forms of arsenic or used as a pesticide, and the $\mathrm{Mg}_{3}\left(\mathrm{PO}_{4}\right)_{2}$ in fertiliser. Recovery of these valuable products from phytoremediation biomass would incentivise and drive commercial industries' participation in remediation of contaminated lands.

Keywords: Phytoremediation, hyper-accumulator, Pteris cretica, solvent extraction, molybdic acid process, arsenic nanoparticles. 


\section{Introduction}

31 Contamination of soils and ground water with arsenic is a serious environmental concern due to 32 numerous associated health risks. Anthropogenic activities such as mining (Asante et al., 2007) or excessive use of arsenic-containing pesticides, and natural leaching of arsenic from the Earth's crust source of arsenic contamination is mining. Examples include arsenic contamination of the soil and ground water in the Ron Phibun District, Nakhan Sri Thammarat Province of Thailand, caused by tin mining, which released arsenopyrite (FeAsS) into the surroundings (Jankong et al., 2007), whereas the contamination at Minas Gerais State in Brazil was caused by gold mining (Schneider et al., 2013). In the UK, now-defunct industrial activities are responsible for long-term soil contamination with various pollutants in many sites in England and Wales, with arsenic contamination present at over $80 \%$ of contaminated sites (Defra, 2014). Arsenic-contaminated soils and ground water are sources of arsenic poisoning in humans, through drinking of the contaminated ground water, or by consuming food grown in contaminated soils and water. Long term consumption of contaminated food and water can lead to chronic arsenic poisoning in animals and humans (Jankong et al., 2007), and the severity the poisoning depends strongly on the dose and duration of exposure. Chronic exposure arsenic has been related to certain dermatological conditions, as well as reproductive, neurological, cardiovascular, respiratory and diabetic effects in humans (Mukherjee et al., 2006). Ingestion of inorganic arsenic has also been linked to skin, bladder and lung cancer (National Research, 1999).

To address the harmful effects of environmental arsenic contaminations, a number of contaminated site remediation strategies now exist, namely excavation and direct landfill disposal (Kumar et al., 1995; Sas-Nowosielska et al., 2004), thermochemical treatments such as incineration, and phytoremediation contamination (Anderson et al., 1999; Reeves, 2000; Rahman et al., 2016). These processes have become very important due to increasing global human population and consequent rise in demand for agricultural land and for development, necessitating cleaning up of former industrial 
55 sites that contain high levels of heavy metals and metalloids contaminations. Excavation of contaminated soil for direct landfill disposal is a costly process when applied to large areas of land, and often relocates the problem rather than solving it, which creates long-term environmental concerns (Sas-Nowosielska et al., 2004). Phytoremediation processes involving the use of hyper-accumulator plants are a widely accepted method in treatment of contaminated sites (Anderson et al., 1999; Reeves, 2000; Rahman et al., 2016).

The hyper-accumulator plants have the ability to accumulate certain amounts of the heavy metal or metalloid contaminants from the soil or groundwater through the roots (Ha et al., 2011). Usually, these plants accumulate different types of heavy metals and metalloids, which leads to selective removal of

the inorganic contaminants, and remediation of the contaminated soils/groundwater. A hyperaccumulator plant must be able to accumulate typically at least $1000 \mathrm{mg}$ per $\mathrm{kg}$ dry biomass for most heavy metals and metalloids ( $\mathrm{As}, \mathrm{Co}, \mathrm{Cu}, \mathrm{Ni}, \mathrm{Se}$, and $\mathrm{Pb}$ ), excluding $\mathrm{Mn}$ and $\mathrm{Zn}$ with threshold concentration of $10,000 \mathrm{mg} \mathrm{kg}^{-1}$, and $100 \mathrm{mg} \mathrm{kg}^{-1}$ for $\mathrm{Cd} \mathrm{kg}$ (Reeves, 2000). For phytoremediation of arsenic contamination, most of the known hyper-accumulators plants are fern species belonging to the Pteris genus (Komar, 1998; Ma et al., 2001; Meharg, 2003; Srivastava et al., 2006), except for Pityrogramma calomelanos species (Meharg, 2003).

Among these fern species, one of the first discovered arsenic hyper-accumulators was Pteris vittata, which achieved $4360 \mathrm{mg} \mathrm{kg}^{-1}$ arsenic accumulation in the fronds, compared to $184 \mathrm{mg} \mathrm{kg}^{-1}$ arsenic in the soil (Komar, 1998). Pteris cretica is one of the reported hyper-accumulators of arsenic that accumulates arsenic to a similar extent as the Pteris vittata (Zhao et al., 2002; Wei and Chen, 2006). The Pteris cretica species are particularly promising for arsenic phyto-remediation in the UK, as these are the top arsenic hyper-accumulators among the locally available ferns (Meharg, 2003). Generally, most of the arsenics accumulated by ferns are stored in the fronds (Srivastava et al., 2006; Jankong et al., 2007), and this informs the usual choice of harvesting the fronds (Meharg, 2003). Arsenic exists in the form of arsenate in well-aerated soils, and this is taken up via the plant roots and then, rapidly 
reduced to arsenite in the xylem and transported to the aerial portions (fronds) of the plant (Su et al., 2008; Han et al., 2017). The active transport and sequestration in the fronds reduces the arsenic toxicity to the plants.

Phytoremediation process generates large amounts of contaminated biomass. In case of remediation of arsenic-contaminated sites, the resulting biomass has limited application due to its high levels of arsenic, and this biomass is often treated as a hazardous waste. Due to the large amounts of contaminated biomass produced in phytoremediation process, volume reductions through thermochemical process is important (Devi et al., 2003; Lievens et al., 2008; Pudasainee et al., 2014). Thermochemical treatment of the wet biomass, mainly through gasification, as a result of the high moisture content (Lievens et al., 2008), generates syngas which is used in production of renewable fuels in an energy efficient manner (Devi et al., 2003). However, emissions of toxic heavy metals and metalloids from the gasification of the contaminated biomass presents significant environmental problems. Indeed, there is need to ascertain the fate of the heavy metals and metalloids during the thermochemical process (Vervaeke et al., 2006; Nzihou and Stanmore, 2013; Pudasainee et al., 2014), and to address any associated technical and environmental challenges (Lievens et al., 2008; Pudasainee et al., 2014). Apart from the potential renewable energy production from thermochemical treatment of arsenic contaminated biomass, there are no investigations on extraction of the arsenics for future application. The contaminated phytoremediation biomass and the resulting fly ash are usually carefully disposed as toxic waste materials.

However, notwithstanding the harmful effects of arsenic, there are promising applications of arsenicderived products in the medical (Waxman and Anderson, 2001; Lu et al., 2002; Li and Huang, 2008; Ahn et al., 2010; Chakraborty et al., 2014), horticultural (Wang and Mulligan, 2006) and electronics (Sheikh et al., 2010; Chen et al., 2012) industries. Arsenic, in the form of the complex gallium arsenide (GaAs), has been extensively used in electronics and optoelectronics as a direct semiconductor, with applications in light-emitting diodes (LEDs), integrated circuits (ICs) and microwave appliances (Chen 
et al., 2012). GaAs has superior electronic properties to silicon and is often used to meet the requirements of advanced technologies, however, GaAs has disadvantages of weak mechanical properties, high production costs and sensitivity to the environmental parameters (Sheikh et al., 2010). In horticulture, arsenical pesticides such as lead arsenate, calcium arsenate and magnesium arsenate are used in pest control (Wang and Mulligan, 2006). However, there are some concerns that this practice could lead to soil and groundwater contamination.

In the medical field, arsenic nanoparticles of $76 \mathrm{~nm}$ sizes were shown to be effective in treatment of extracellular and intracellular proliferation of Leishmania donovani (Chakraborty et al., 2014). Also, arsenic-based compounds have found applications in treatment in haematological malignancies. Researchers have shown that arsenic particles possess properties that may be used to treat solid tumour cancers, such as breast cancer, when used in nanoscale size (Li and Huang, 2008). Arsenic in the form of $\mathrm{As}_{2} \mathrm{O}_{3}$ and $\mathrm{As}_{4} \mathrm{~S}_{4}$ are the most widely reported arsenic-based cancer drugs for treatment of acute promyelocytic leukaemia (APL) (Waxman and Anderson, 2001; Lu et al., 2002). The $\mathrm{As}_{2} \mathrm{O}_{3}$ was originally used for the treatment of skin diseases and asthma in Chinese traditional medicine, and clinical trials conducted at Shanghai Second Medical University showed that it was effective in patients with newly diagnosed and relapsed acute promyelocytic leukaemia, with complete remission in 6 out of the 7 (Waxman and Anderson, 2001). Currently, arsenic trioxide is being used to treat patients with APL. However, the treatment is dose limiting due to the toxicity of $\mathrm{As}_{2} \mathrm{O}_{3}$, and this makes the stay of the arsenic trioxide in the body not long enough to treat solid cancers at these low doses. rapid renal clearance which limits the uptake of the arsenic oxide, and the dose-limiting toxicity (Maeda et al., 2004). Arsenic in the form of $\mathrm{As}_{4} \mathrm{~S}_{4}$ is highly effective and safe in both remission induction and maintenance therapy in patients with APL when administered alone, regardless of disease stage (Lu et al., 2002). The $\mathrm{As}_{4} \mathrm{~S}_{4}$ is almost insoluble in aqueous solution and much less toxic with better tolerance, in comparison to patients treated with arsenic trioxide (Baláž and Sedlák, 2010). 
130 Nanoscale drug carriers was proposed to increase the therapeutic index of cytotoxic drugs, by 131 increasing drug delivery, enhancing antitumor efficacy, and reducing systematic toxicity (Li and 132 Huang, 2008; Ahn et al., 2010). Use of arsenics nanoparticles of less than 350nm sizes could be 133 effective for nano-drug penetration into a tumour body, considering the vasculature of tumour which 134 has been found to have low pH (i.e. acidic) environments (Ahn et al., 2010), and are highly abnormal, proliferative and tortuous with pores between 350-800 nm (Baláž and Sedlák, 2010). Therefore, nanoparticles of arsenics for anti-cancer drugs can target tumour cells whilst protecting normal cells, through encapsulated delivery in $\mathrm{pH}$-sensitive materials to prevent premature activation during its transport.

Recent studies have shown some interests in recovery of arsenic and other metal(loid)s from hyperaccumulator biomass, and their conversions to valuable products. A preliminary study using a Monte Carlo simulation has demonstrated that recovery of contaminant elements, such as arsenic, nickel and platinum from the phyto-accumulator biomass would increase the financial viability of phytoremediation of soils contaminated with heavy metals and metalloids (Jiang et al., 2015). The uptake of valuable metal(loid)s elements from the soil using hyper-accumulator plants, also called phyto-mining, has been proposed for recovery of precious metals such as nickel from low-grade ores (van der Ent et al., 2015). Therefore, extractive valorisation of heavy metal(loid)s elements in hyperaccumulator biomass is expected to drive the global land remediation projects and allows for more economic mining of precious metal(loid)s from low-grade ores.

The aim of this study is to develop a process for integrated phytoremediation of arsenic-contaminated soils, and synthesis of valuable arsenic products. The phytoremediation biomass from the decontamination of arsenic-contaminated soils is a cheap raw material for extraction of valuable chemical element and compounds of arsenic. Therefore, this study investigates the phytoremediation efficiency of ferns (Pteris cretica), and sequestration of the phyto-accumulated arsenic in the form of magnesium arsenate (a potential pesticide) and subsequent conversion of this to arsenic nanoparticles 
155 for medical applications. The study attempts to create value-added products from the contaminated 156 phytoremediation biomass, to act as an incentive, which will motivate industry participation in 157 remediation of contaminated soils and groundwater, both in the UK and globally. Remediation of 158 contaminated soils and groundwater is capital intensive, and this requires government funding, 159 therefore, it is expected that a process that extracts products of commercial interest would attract 160 industry participation.

\section{2. Materials and methods}

\section{2.1. Materials and analytical equipment}

163 The materials used in the experiments were sodium arsenate dibasic heptahydrate, $(98 \%$, Sigma164 Aldrich), perchloric acid (70\% and $\geq 99.999 \%$ trace metals basis, Sigma-Aldrich), nitric acid (70\% and $\geq 99.999 \%$ trace metals basis, Sigma-Aldrich), hydrogen peroxide solution $(\geq 30 \%$ for trace analysis, Sigma-Aldrich), isobutyl acetate (99\%, Sigma-Aldrich), oleylamine (98\%, Sigma-Aldrich), tributyl phosphate (99\%, Sigma-Aldrich), sodium borohydride (99.99\% trace metals basis, SigmaAldrich), L-cysteine (97\%, Sigma-Aldrich), hydrochloric acid (37\% for trace metal analysis, Fisher trace metals basis, Sigma-Aldrich), TraceCERT inorganic arsenic, phosphorus, and potassium standards for ICP (1000 $\mathrm{mg} \mathrm{kg}^{-1}$, Sigma-Aldrich), low odour reagent grade kerosene (Sigma-Aldrich), and 0.45 PTFE syringe filters (SGE, UK). Other materials used for the study were Pteris cretica Albolineata ferns from Shady Plants (a specialist fern nursery in Ireland), and $100 \%$ peat-free allgrowing medium for plant cultivation in a laboratory environment (Drake et al., 2016). The Pteris cretica Albolineata ferns are a relatively inexpensive plant and are found growing all over the World, making them a suitable for an arsenic phytoremediation study. The Pteris cretica species are particularly promising for arsenic phyto-remediation projects in the UK, as these are the top arsenic hyper-accumulators among the locally available ferns (Meharg, 2003). The equipment used were a 
Weiss Gallenkamp Fitotron growth cabinet, Memmert 100-800 model drying oven, a Mettler Toledo S975 SevenExcellence ${ }^{\mathrm{TM}}$ (pH, Conductivity, Dissolved Oxygen), a Varian Vista-MPX CCD Simultaneous Inductively Coupled Plasma - Optical Emission Spectroscopy (ICP-OES), Philips CM 100 Compustage (FEI) Transmission Electron Microscope (TEM) equipped with an AMT CCD camera (Deben) for acquiring digital images, a Hitachi S2400 Scanning Electron Microscope (SEM) with Field Emission Gun (FEI X30 ESEM-FEG) and equipped with energy dispersive X-ray microscopy (EDX) based on Rontec Quantax software for analysis of elemental compositions, and an Elementar Vario Max CNS Analyser for determinations of total carbon, nitrogen and sulphur contents of the compost.

The Westland all-purpose compost used was analysed using existing methods for determinations of compost properties (Afifi et al., 2012). It had a moisture content of $31.0 \pm 2.6 \%$ (by oven drying method) and $648 \pm 30.7 \mathrm{~kg} \mathrm{~m}^{-3}$ bulk density. Chemical properties of the compost were $\mathrm{pH}$ of $6.2 \pm 0.5$ and electrical conductivity of $32 \pm 1.4 \mathrm{mS} \mathrm{cm}^{-1}$ using Mettler Toledo S975 SevenExcellenceTM, and elemental compositions of $20.6 \pm 1.2 \%$ total carbon, $1.50 \pm 0.18 \%$ total nitrogen, and $0.32 \pm 0.03 \%$ sulphur using the Elementar Vario Max CNS Analyser. Other chemical properties of the compost as determined by the ICP-OES analysis of digested compost samples were $0.96 \pm 0.08 \%$ phosphorus, $1.63 \pm 0.15 \%$ potassium, and $0.52 \pm 0.18 \mathrm{mg} \mathrm{kg}^{-1}$ of arsenic.

\subsection{Controlled phytoremediation of soil contaminated with arsenic using Pteris cretica ferns}

In the phytoremediation study, 10 individual Pteris cretica ferns were received from the Shady Plants and potted immediately on delivery. The individual ferns were transferred to $10 \mathrm{~cm}$ pots containing $1000 \mathrm{~g}$ of the compost. Seven of the 10 pots of compost were spiked with sodium arsenate dibasic heptahydrate $\left(\mathrm{Na}_{2} \mathrm{HAsO}_{4} .7 \mathrm{H}_{2} \mathrm{O}\right)$ to achieve $200 \mathrm{mg} \mathrm{kg}^{-1}$ of arsenic contamination in the soil. The three remaining pots of ferns were left to grow as control samples, without any arsenic contaminations. The 10 potted ferns were marked and then placed in the Weiss Gallenkamp Fitotron growth cabinet, and they were left to grow in a controlled environment inside the growth cabinet as shown in Fig. 1. 

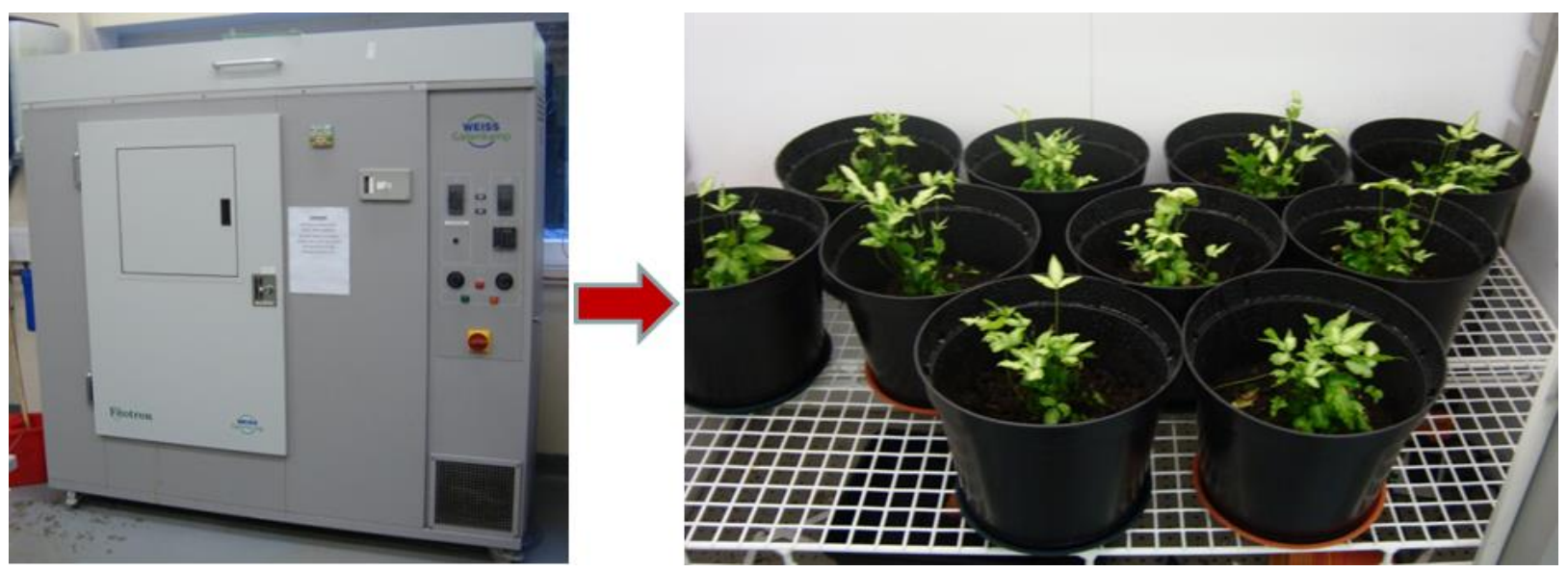

Fig. 1. Pteris cretica 'Albolineata ferns growing in contaminated soil in Weiss Gallenkamp Fitotron growth cabinet.

The growth conditions were: $16 \mathrm{~h}$ light per day, light intensity of $350 \mu \mathrm{mol} \mathrm{m} \mathrm{m}^{-2} \mathrm{~s}^{-1}$, temperatures set to $25{ }^{\circ} \mathrm{C}$ for day and $20{ }^{\circ} \mathrm{C}$ for night, and relative humidity of $60-70 \%$. The arsenic uptake by the ferns was monitored by determinations of the arsenic contents of the fronds. Samples of the Pteris cretica

fronds were harvested by carefully cutting a few fronds from each pot, as reported elsewhere (Meharg, 2003). The Pteris cretica fronds were harvested from the 7 arsenic-contaminated pots and combined, and same for the control pots. The ferns harvesting was done at time intervals from $0-60$ days to monitor the arsenic content. The ferns continued to grow and there was no evidence that the harvesting method was harmful to their growth and arsenic uptake. The controlled phytoremediation of Ascontaminated soil was repeated twice to determine the optimum growth time required to attain maximum As accumulation in the biomass. This optimum was used in all subsequent phytoremediation trials.

\subsection{Solvent extractions and determinations of total and extracted arsenics in the ferns biomass}

The total arsenic content of the fern biomass was determined after digestion using nitric acid and hydrogen peroxide as reported elsewhere (Cai et al., 2000; Zhang et al., 2002; Liu et al., 2013; Costa et al., 2016). Use of a combination of the $\mathrm{HNO}_{3}$ and $\mathrm{H}_{2} \mathrm{O}_{2}$ has been found to be the most suitable digestion medium for seagrass biomass in determinations of arsenic (Cai et al., 2000). The harvested ferns biomass (fronds) from the contaminated soil and the controls were rinsed 3 times with deionised 
water and dried to constant weights in Memmert 100-800 model oven at $105^{\circ} \mathrm{C}$ for $12 \mathrm{~h}$. About $0.1-$

$2270.5 \mathrm{~g}$ of the dried biomass were weighted into a $100 \mathrm{~mL}$ round-bottom flask, followed by additions of $10 \mathrm{~mL}$ of $\mathrm{HNO}_{3}$ per $0.1 \mathrm{~g}$ of biomass. The biomass was heated in the $\mathrm{HNO}_{3}$ medium at $100{ }^{\circ} \mathrm{C}$ for 2 hours with occasional swirling, and then cooled to $70^{\circ} \mathrm{C}$. Hydrogen peroxide solution in the range of $1 \mathrm{~mL}$ per $0.1 \mathrm{~g}$ ferns was added to the digestion mixture, followed by further heating at $100{ }^{\circ} \mathrm{C}$ for 30min, and the solution was reduced to a few millilitres $(\sim 10 \mathrm{~mL})$ by evaporation. The digestion mixture was quantitatively transferred into a $50 \mathrm{~mL}$ volumetric flask and diluted to the mark using $5 \%$ $\mathrm{HNO}_{3}$ in deionised water. These samples were used to determine the total arsenic contents of the Pteris cretica fronds.

Solvent extraction of arsenic from the Pteris cretica biomass was also investigated. About $0.5 \mathrm{~g}$ of dried fronds biomass was extracted with $25 \mathrm{~mL}$ of either water, ethanol-water $(1: 1 \mathrm{v} / \mathrm{v})$, or methanolwater $(1: 1 \mathrm{v} / \mathrm{v})$. The extraction was conducted for $2 \mathrm{~h}$ using a round-bottom flask equipped with a heater-stirrer set at room temperature $\left(25^{\circ} \mathrm{C}\right)$ and $540 \mathrm{rpm}$ mixing intensity. The samples were centrifuged at $3000 \mathrm{rpm}$ in $50 \mathrm{~mL}$ centrifuge tubes to recover clear supernatants, and the residues were rinsed thrice with $25 \mathrm{~mL}$ of the extracting solvent each time. All the supernatants were combined and made up to a total volume of $100 \mathrm{~mL}$ using $5 \mathrm{wt} \% \mathrm{HNO}_{3}$ in deionised water.

242 All the samples solutions from the fern biomass digestion and solvent extractions were filtered into 50 $\mathrm{mL}$ PTFE tubes using $0.45 \mu \mathrm{m}$ PTFE syringe filter (SGE), and stored in a fridge at $4{ }^{\circ} \mathrm{C}$ for analysis. 244 These samples were analysed, either directly or diluted with the $5 \mathrm{wt} \% \mathrm{HNO}_{3}$ in deionised water, using Varian Vista-MPX CCD Simultaneous ICP-OES. All the apparatus used in the experiments (roundbottom digestion flask, volumetric flasks, glass funnels, PTFE tubes) were soaked overnight in a deionised water containing $5 \mathrm{wt} \% \mathrm{HNO}_{3}$ and rinsed 3 times with deionised water. Standard curve for the arsenic and phosphorus quantifications were prepared by dilutions of the $1000 \mathrm{mg} \mathrm{kg}^{-1} \mathrm{TraceCERT}^{-}$ inorganic arsenic and phosphorus standards with $5 \mathrm{wt} \% \mathrm{HNO}_{3}$ in deionised water, to obtain $0,0.5,1$, 2, 4, 8 and $10 \mathrm{mg} \mathrm{kg}^{-1}$ standard solutions. This procedure was also followed to measure the arsenic, 
phosphorus, and potassium in the compost. All the arsenic, phosphorus and potassium determinations were carried out in duplicates. The quantification of these elements using ICP-OES was based on calibration curves for standard solutions at multiple specific wavelength channels with high linear correlation $\left(\mathrm{R}^{2}>0.999\right)$. Measurements at multi-channels is a useful technique that detects interferences by other elements in any of the wavelengths.

\subsection{Extractions of valuable products from digested ferns biomass in a molybdic acid process}

257 Extractions of arsenic from the ferns biomass substantially reduced the volume of biomass to be extracted arsenic was converted to the inorganic form. This was achieved by evaporating the extracting described for the total arsenic determination. In a large-scale process, the evaporated ethanol and water would be condensed and recycled. The digested biomass extract was evaporated to near dryness at $100^{\circ} \mathrm{C}$ and cooled to room temperature $\left(25^{\circ} \mathrm{C}\right)$. This was followed by addition of $25 \mathrm{~mL}$ of deionised water and about $1 \mathrm{~mL}$ of perchloric acid to obtain a test solution for the molybdic acid process. Additions of perchloric acid prevents any formations of silicomolybdic acid in the molybdic process (Shraim et al., 2000).

About $12 \mathrm{~mL}$ of the test solution was transferred into a $50 \mathrm{~mL}$ separating funnel, and $4 \mathrm{~mL}$ of $5 \%(\mathrm{w} / \mathrm{v})$ of molybdenum prepared as a sodium molybdate in deionised water was added followed by vigorous shaking to mix the contents of the separating funnel. More deionised water was added to maintain the $\mathrm{pH}$ of the solution at about $0.8-1$, which are required for complete formation of the arseno- and phospho-molybdic acid complexes (Paul, 1966; Hamiti et al., 1985). The mixture in the separating funnel was allowed to stand for about $20 \mathrm{~min}$ for the complete molybdic acid complexes formation. The phosphomolybdic acid complex was selectively extracted using isobutyl acetate (Paul, 1966). 20 $\mathrm{mL}$ of isobutyl acetate was added into the separating funnel after the complete formation of the 

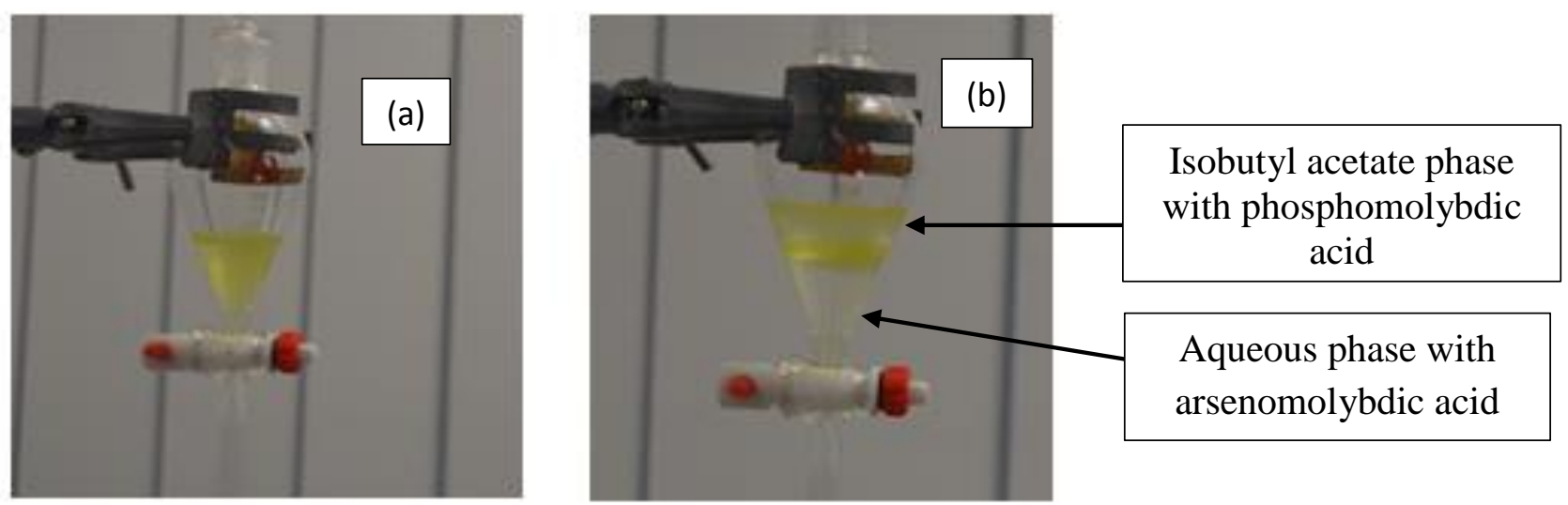

279 Fig. 2. Extraction procedure - (a) formation of mixtures of molybdic acid complexes of arsenic and phosphorus, (b) selective extraction of phosphomolybdic acid complex into isobutyl acetate

Aqueous phase (bottom layer) from the phosphomolybdic acid extraction contained the arsenomolybdic acid complex. The aqueous layer was transferred into another separating funnel, and the $\mathrm{pH}$ was adjusted to $6.5-7 \mathrm{using} 1 \mathrm{M} \mathrm{NaOH}$ solution $(\sim 2 \mathrm{~mL})$. It was then mixed with $20 \mathrm{~mL}$ of an extracting solvent containing a mixture of 1 vol\% oleylamine as a primary amine $\left(\mathrm{RNH}_{2}\right)$ and 10 vol\% tributyl phosphate (TBP) in kerosene, as previously reported (Zhao and Chen, 1996). The mixture was shaken vigorously for 2 to $3 \mathrm{~min}$ in the separating funnel and allowed to stand for about $15 \mathrm{~min}$ for complete separation of the aqueous and organic layers.

The phosphomolybdic and arsenomolybdic acid complexes were stripped from the extracting organic solvents into an aqueous phase using approximately equal volume of $0.1 \mathrm{M} \mathrm{NaOH}$ solution at equilibrium $\mathrm{pH}$ of $8-10$. At these conditions, quantitative stripping of the molybdic acid complexes from the organic phase occurs (Zhao and Chen, 1996). The aqueous solutions from phosphate and arsenate stripping were selectively precipitated by treatment with aqueous $\mathrm{MgCl}_{2}$ at 1:3 molar ratio of phosphorus/arsenic to magnesium at $25^{\circ} \mathrm{C}$ (Park et al., 2010), leading to formation of white solids of $\mathrm{Mg}_{3}\left(\mathrm{PO}_{4}\right)_{2}$ and $\mathrm{Mg}_{3}\left(\mathrm{AsO}_{4}\right)_{2}$, which are insoluble in water at these conditions. A flow diagram 
summarising the arsenic and phosphorus extraction processes is shown in Fig. 3. The amounts of arsenic and phosphorus extracted into the organic phases were determined through IC-OES analysis of the aqueous phases, before and after extractions with isobutyl acetate and $\mathrm{RNH}_{2} \& \mathrm{TBP}$ in kerosene. The aqueous phases from the arsenate and phosphate stripping were also analysed to quantify the amounts of arsenic and phosphorus recovered.

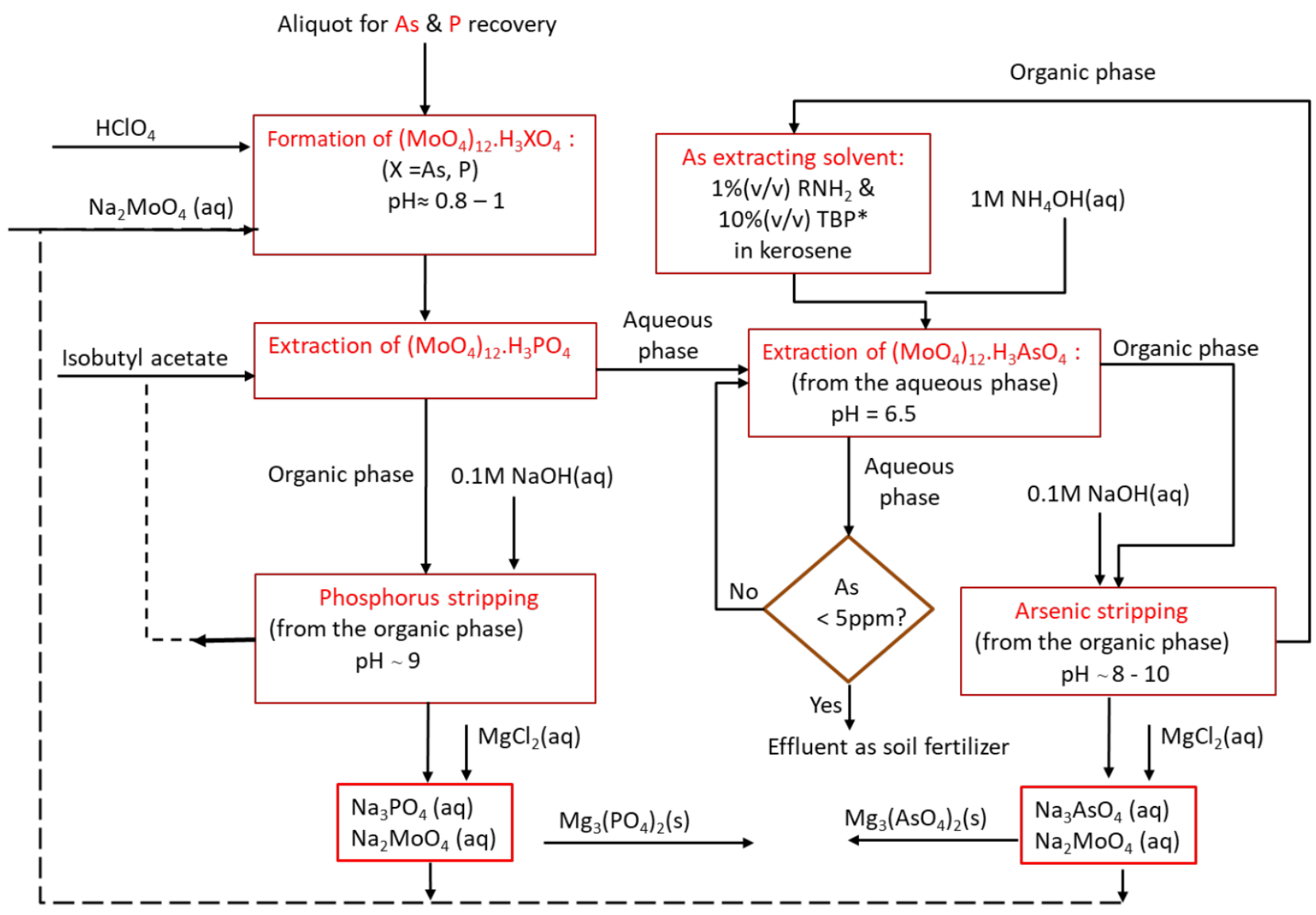

Fig. 3. Flow diagram for the extractions of arsenic and phosphorus from digested biomass using molybdic acid process. $\mathrm{Mg}_{3}\left(\mathrm{AsO}_{4}\right)_{2}$ could be converted to more valuable forms of arsenic, or used as

\subsection{Productions of arsenic nanoparticles from the Pteris cretica-derived arsenate}

Arsenic nanoparticles were obtained from the $\mathrm{Mg}_{3}\left(\mathrm{AsO}_{4}\right)_{2}$ derived from the ferns biomass, through a combination of pre-reduction with L-cysteine, followed by $\mathrm{NaBH}_{4}$ reduction. This procedure was a modification of a wet-chemical method for synthesis of arsenic nanoparticles from As(III) in an 
existing study (Pal et al., 2012). About $0.25 \mathrm{~g}$ of the $\mathrm{Mg}_{3}\left(\mathrm{AsO}_{4}\right)_{2}$ was dissolved with $2 \mathrm{~mL}$ of concentrated $\mathrm{HCl}$ in a $100 \mathrm{~mL}$ round-bottom, followed by addition of $50 \mathrm{~mL}$ of deionised water and heating at $80{ }^{\circ} \mathrm{C}$ for $30 \mathrm{~min}$. The resulting arsenate solution was transferred into $100 \mathrm{~mL}$ volumetric flask and made up to the mark using deionised water. This solution contained approximately $0.01 \mathrm{M}$ of $\mathrm{As}(\mathrm{V})$ at $\mathrm{pH}$ of about 2 and was used for the arsenic nanoparticles synthesis. $50 \mathrm{~mL}$ of the $\mathrm{As}(\mathrm{V})$ solution was heated for $2 \mathrm{~h}$ with $0.2(\mathrm{w} / \mathrm{v}) \%$ of L-cysteine based on the arsenate solution using a 100 mL flask at $60{ }^{\circ} \mathrm{C}$ and $540 \mathrm{rpm}$ mixing, reducing the $\mathrm{As}(\mathrm{V})$ to $\mathrm{As}(\mathrm{III})$ as shown in the reaction equation 317 in Fig. 4(a).
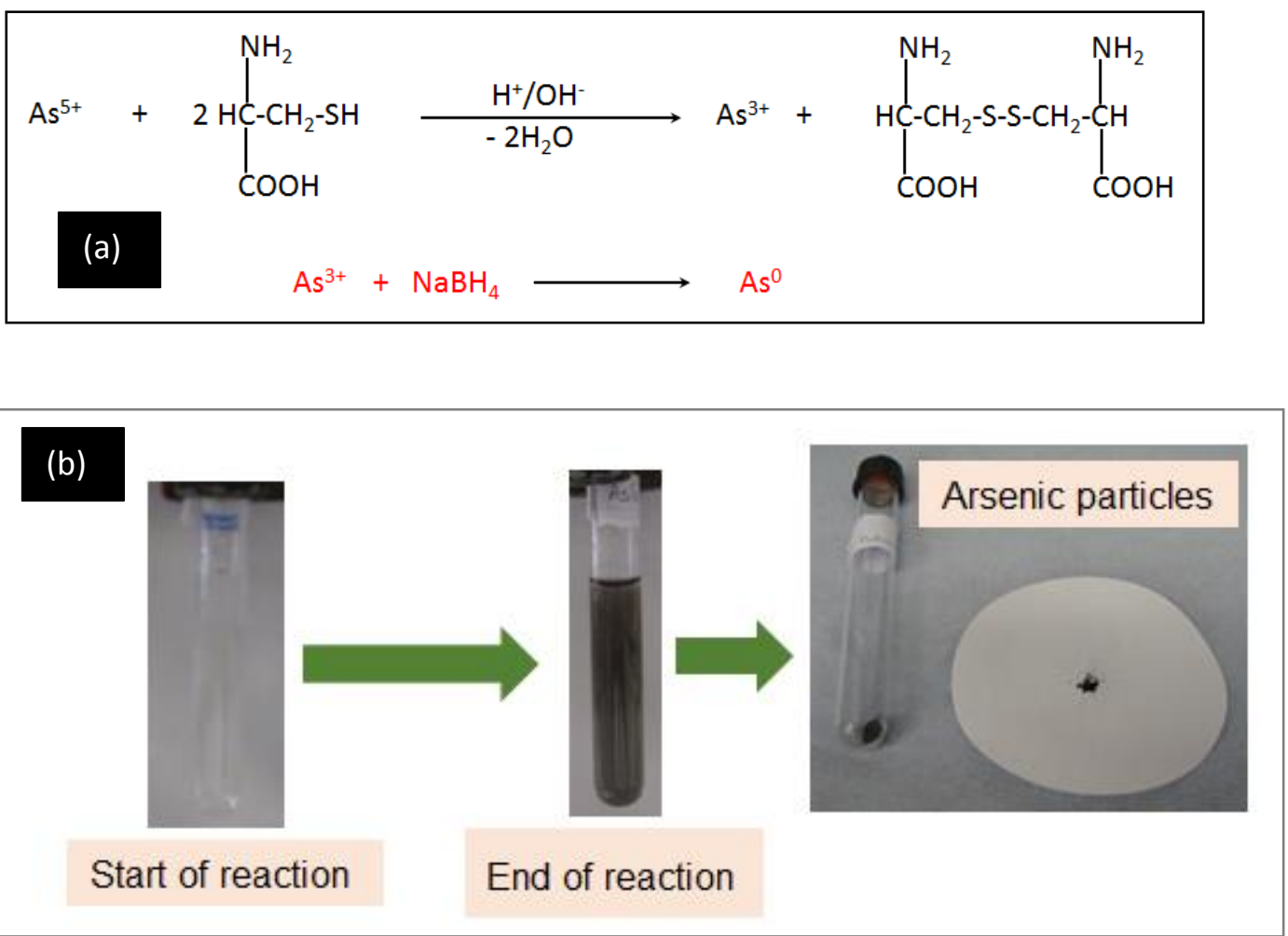

Fig. 4. Production of arsenic nanoparticles: (a) reaction scheme involving pre-reductions of $\mathrm{As}^{5+}$ in $\mathrm{L}$ -

The resulting As(III) solution was cooled to room temperature, neutralised with a $0.1 \mathrm{M} \mathrm{NaOH}$ until cysteine followed by $\mathrm{NaBH}_{4}$ reduction of $\mathrm{As}^{3+}$ to arsenic particles, (b) samples at the start and end of reactions, and after separation and drying of the particles. the $\mathrm{pH}$ was adjusted to $7-9$, and filtered using $0.45 \mu \mathrm{m}$ syringe filter (SGE, UK). About $10 \mathrm{~mL}$ of the filtrate was reacted for $2 \mathrm{~h}$ with an equal volume of a $0.1 \mathrm{M} \mathrm{NaBH}_{4}$ in a $50 \mathrm{~mL}$ flask at $25{ }^{\circ} \mathrm{C}$ and 540 
328 rpm mixing, and this was followed by heating the mixture at $60{ }^{\circ} \mathrm{C}$ for another $30 \mathrm{~min}$. Brownish329 coloured particles of $\mathrm{As}(0)$ were formed. The $0.1 \mathrm{M} \mathrm{NaBH}_{4}$ used was prepared in an ice-cold water $(\sim 5$

$330{ }^{\circ} \mathrm{C}$ ) to minimise aqueous decomposition of the $\mathrm{NaBH}_{4}$ and loss of the nascent hydrogen required for 331 the As(III) reduction. The arsenic particles produced (Fig. 4(b)) were washed three times using equal 332 volumes of deionised water and centrifuged each time at $3000 \mathrm{rpm}$ to recover the particles. The 333 recovered particles were analysed for their morphology and particle size distribution using TEM, and 334 EDX to determine the elemental composition. The TEM images were analysed for the particles size 335 distribution using ImageJ software.

\section{3. Results and Discussions}

337 3.1 Hyper-accumulation and solvent extractions of arsenic from Pteris cretica biomass

338 The total arsenic accumulation on the Pteris cretica fronds, as determined using the ICP-OES, are 339 shown in Fig. 5(a). Arsenic content in the harvested fronds increased from $1087 \pm 65 \mathrm{mg} \mathrm{kg}^{-1}$ after 7 $340 \mathrm{~d}$ to $3770 \pm 85 \mathrm{mg} \mathrm{kg}^{-1}$ after $21 \mathrm{~d}$. Maximum As content in the accumulation study with intermittent 341 biomass harvesting was $4427 \pm 79 \mathrm{mg}$ per $\mathrm{kg}$ of dry ferns after 30 days. There was a negligible As 342 content $\left(15.1 \pm 1.7 \mathrm{mg} \mathrm{kg}^{-1}\right)$ in the Pteris cretica fronds from the control experiments. The level of 343 arsenic in the Pteris cretica biomass from the arsenic-contaminated soil exceeds the $1000 \mathrm{mg} \mathrm{kg}^{-1}$ 344 threshold required for a plant to be classified as a hyper-accumulator of arsenic (Reeves, 2000). 

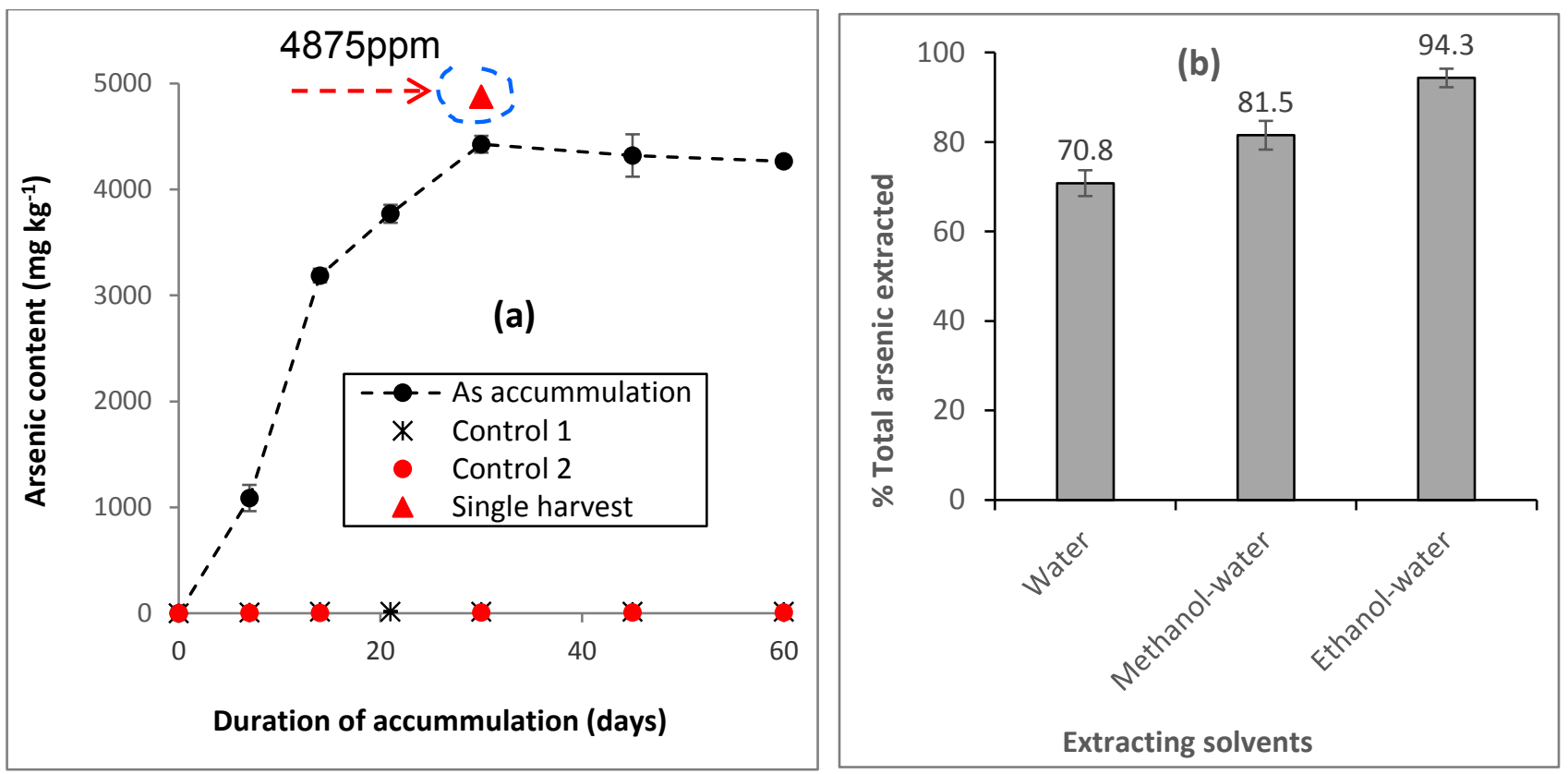

Fig. 5. (a) Arsenic contents in Pteris cretica fronds as a function of the duration of accumulation, (b) percentage of the total biomass arsenic contents extracted using various solvents.

The arsenic concentration of the Pteris cretica obtained from this work are consistent with $4360 \mathrm{mg}$ $\mathrm{kg}^{-1}$ which has been reported for Pteris vittata grown in soil containing $184 \mathrm{mg} \mathrm{kg}^{-1}$ of arsenic (Komar, 1998). However, these values are much lower than $7346 \pm 447 \mathrm{mg} \mathrm{kg}^{-1}-7714 \pm 70.5 \mathrm{mg} \mathrm{kg}^{-1}$ reported for Pteris vittata grown on soil contaminated with $200 \mathrm{mg} \mathrm{kg}^{-1}$ of arsenate (Zhao et al., 2015). Generally, these studies indicate that ferns that belong to the Pteris genius have the capacity for arsenic hyper-accumulation.

There was a slight drop in As content from $4427 \mathrm{mg} \mathrm{kg}^{-1}$ at $30 \mathrm{~d}$ to $4264 \mathrm{mg} \mathrm{kg}^{-1}$ after $60 \mathrm{~d}$, for the accumulation with intermittent biomass harvesting, as shown in the Fig. 5(a). This was attributed to increased lignocellulosic matter in the ferns with age. It was observed that the arsenic content of the Pteris cretica that was grown and harvest once, all at $30 \mathrm{~d}$, were slightly higher than those obtained with intermittent harvesting. For instance, the maximum As contents of the Pteris cretica after 30days were $4427 \pm 79 \mathrm{mg} \mathrm{kg}^{-1}$ for intermittent harvesting, as compared to $4875 \pm 96 \mathrm{mg} \mathrm{kg}^{-1}$ when harvested at once at $30 \mathrm{~d}$. This observation was attributed to the more steady and uninterrupted growth of the ferns in the Weiss Gallenkamp Fitotron cabinet for the single harvest experiments. In the experimental investigations of arsenic uptake with time, the growth cabinet was intermittently stopped at time 
intervals for Pteris cretica biomass collections. The bulk Pteris cretica fronds collected in the single harvesting was analysed for total arsenic, and this biomass was also utilised for the arsenic solventextraction experiments.

Results of the extractions of arsenic from the Pteris cretica fronds using ethanol-water, methanolwater and water alone are shown in Fig. 5(b). These results show that the highest arsenic extraction of $94.3 \pm 2.1 \%$ was achieved with the ethanol-water $(1: 1 \mathrm{v} / \mathrm{v})$. The extraction efficiency for the $1: 1(\mathrm{v} / \mathrm{v})$ methanol-water was $81.5 \pm 3.2 \%$, and $70.8 \pm 2.9 \%$ for water alone. Analysis of variances using Minitab statistical software showed that ethanol $(\mathrm{p}=0.000)$ and methanol $(\mathrm{p}=0.013)$ had significant effects $(\mathrm{p}<0.05)$ on the arsenic extraction compared to only water. There was also a significant arsenic alone can extract substantial amounts of the total arsenic in the Pteris cretica fronds. This is attributed to the presence of arsenic in ferns biomass mainly in the form of water extractable inorganic species, cretica fronds, addition of some organic solvents to the water helps in recovery of organoarsenics from 
391 The arsenic extraction efficiency of ethanol-water $(94.3 \pm 2.1 \%)$ achieved in this study was consistent with $>90 \%$ obtained for Pteris vittata fronds (Zhao et al., 2015), and this was the highest the arsenic recovery among the three extracting solvents used in this study. Higher arsenic extraction using ethanol-water could be due to the better solubility of organoarsenics in ethanol compared to water and methanol. Another advantage of ethanol-water system over methanol-water is that, methanol is toxic and produces hazardous wastes (Zhao et al., 2015).

\subsection{Recovery of arsenic from the molybdic acid process}

Use isobutyl acetate and 1 vol\% primary amine and 10 vol\% tributyl phosphate in kerosene for extraction were found to be effective in recovery of arsenic and phosphorus in the forms of arsenomolybdic and phosphomolybdic acid complexes from the digested Pteris cretica biomass.

Extraction efficiencies for the molybdic acid complexes were $90.8 \pm 5.3 \%$ and $95.1 \pm 4.6 \%$ for arsenic and phosphorus, respectively. The extraction efficiencies for molybdic acid complexes were quantitative and comparable to that reported elsewhere, for phosphomolybdic acid using the butyl tributyl phosphate in kerosene (Zhao and Chen, 1996). The arsenic and phosphorus in the aqueous phases after stripping were quantitatively precipitated as $\mathrm{Mg}_{3}\left(\mathrm{AsO}_{4}\right)_{2}$ and $\mathrm{Mg}_{3}\left(\mathrm{PO}_{4}\right)_{2}$ on treatment with excess $\mathrm{MgCl}_{2}$ solution, resulting in recovery of about $94 \pm 3.4 \%$ of the phosphorus and $96 \pm 7.2 \%$ of the arsenic. The $\mathrm{Mg}_{3}\left(\mathrm{AsO}_{4}\right)_{2}$ removed compares well with about $98.9 \%$ recovery reported using similar process for removal of arsenate from a molybdate plant liquor (Park et al., 2010), and similar recovery efficiency was achieved for the $\mathrm{Mg}_{3}\left(\mathrm{PO}_{4}\right)_{2}$. Similarity in the recovery efficiencies of the magnesium arsenate and phosphate was attributed to their comparable solubility product constants (Ksp), which are $2.10 \times 10^{-20}$ for $\mathrm{Mg}_{3}\left(\mathrm{AsO}_{4}\right)_{2}, 1.0 \times 10^{-25}$ for $\mathrm{Mg}_{3}\left(\mathrm{PO}_{4}\right)_{2}$, and 2.4 x $10^{-1}$ for $\mathrm{MgMoO}_{4}$ at $25^{\circ} \mathrm{C}(\mathrm{Park}$ et al., 2010). These Ksp values correspond to $0.50 \mathrm{M}, 4.6 \times 10^{-4} \mathrm{M}$, and $3.9 \times 10^{-5} \mathrm{M}$ concentrations for 
the $\mathrm{MgMoO}_{4}, \mathrm{Mg}_{3}\left(\mathrm{AsO}_{4}\right)_{2}$, and $\mathrm{Mg}_{3}\left(\mathrm{PO}_{4}\right)_{2}$ respectively, indicating a wide operating window for quantitative selective precipitations of $\mathrm{Mg}_{3}\left(\mathrm{AsO}_{4}\right)_{2}$ and $\mathrm{Mg}_{3}\left(\mathrm{PO}_{4}\right)_{2}$ from the aqueous molybdate solutions after arsenate and phosphate stripping. The findings from this study demonstrate that soil contaminated with arsenic can be cleaned through phytoremediation, with recovery of $\mathrm{Mg}_{3}\left(\mathrm{PO}_{4}\right)_{2}$ as a potential soil fertiliser. The $\mathrm{Mg}_{3}\left(\mathrm{AsO}_{4}\right)_{2}$ recovered could be stored safely, potentially used as pesticide powder, or converted into other useful forms of arsenic such as arsenic nanoparticles, arsenic trioxide for cancer treatment, and gallium arsenide for electronic applications.

\subsection{Conversions of magnesium arsenate from the molybdic acid process to arsenic nanoparticles.}

Fig. 6(a) shows one of the TEM images for the arsenic nanoparticles produced from the $\mathrm{Mg}_{3}\left(\mathrm{AsO}_{4}\right)_{2}$ using a combination of pre-reduction to $\mathrm{As}(\mathrm{III})$ with L-cysteine and $\mathrm{NaBH}_{4}$ reduction to $\mathrm{As}(0)$. The TEM images were analysed using ImageJ software to obtain the particle sizes distributions shown in the Fig. 6(b).
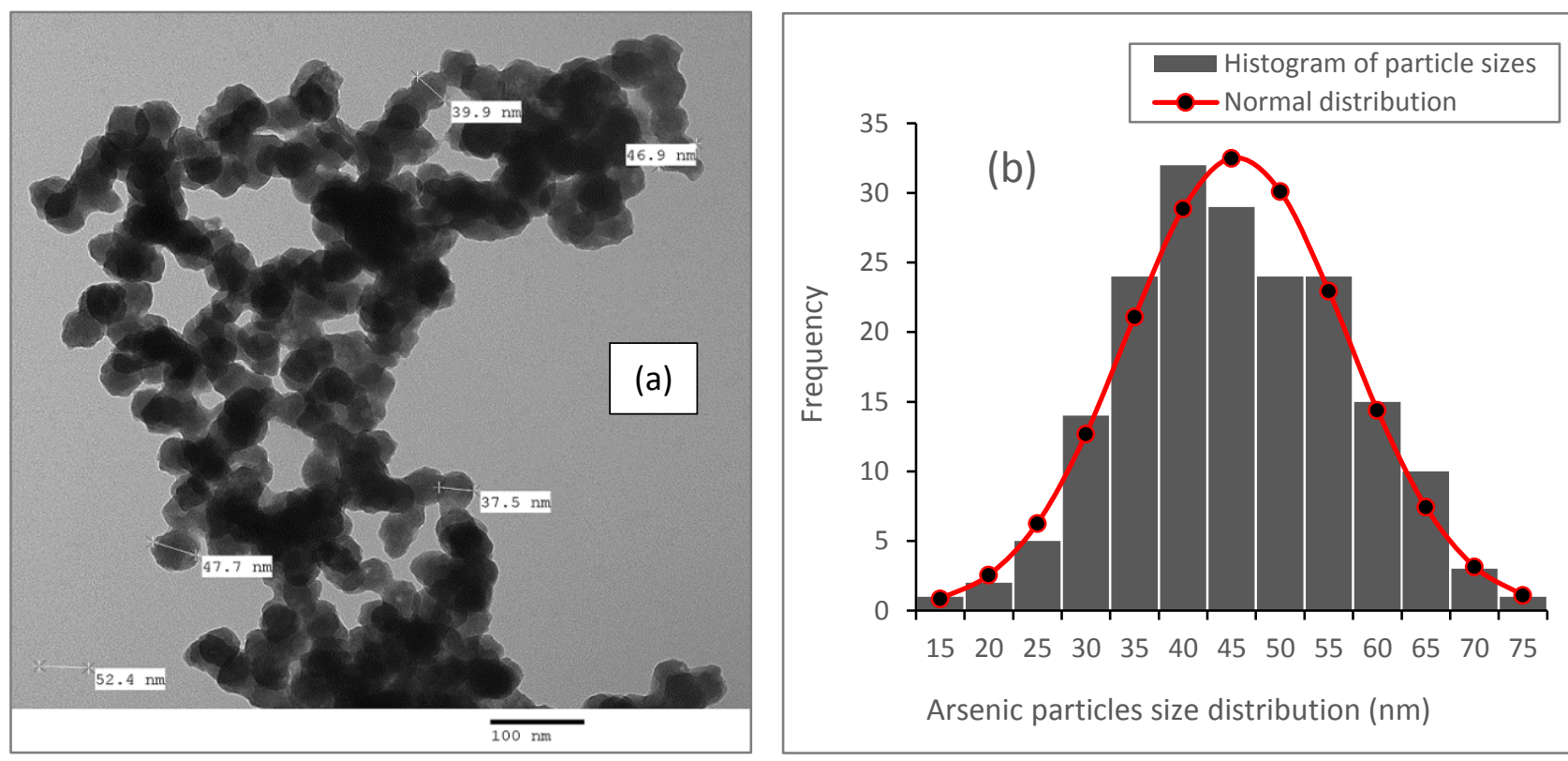

Fig. 6. Arsenic nanoparticles production: (a) TEM image of arsenic nanoparticles from biomass extract, (b) histogram and normal distributions of the arsenic particle sizes.

The TEM image in Fig. 6(a) clearly shows that the particles are close to spherical, with diameters ranging from $15-75 \mathrm{~nm}$, and average particle diameter of $45.5 \pm 11.3 \mathrm{~nm}$. The average particles 
diameters obtained here were slightly less than $60 \pm 3 \mathrm{~nm}$ (Pal et al., 2012), and 76nm (Chakraborty et al., 2014), which have been previously reported. No As nanoparticles were formed when the As(V) solution was treated with $\mathrm{NaBH}_{4}$ without pre-reduction using L-cysteine. This was attributed to $\mathrm{HNO}_{3}$ oxidation of the arsenics to $\mathrm{As}(\mathrm{V})$ during digestion, and $\mathrm{As}(\mathrm{V})$ formed cannot be reduced to As (0) by the $\mathrm{NaBH}_{4}$ at $\mathrm{pH}$ of $7-9$. The arsenic nanoparticles produced have potential applications in treatment of extracellular and intracellular proliferation of Leishmania donovani (Chakraborty et al., 2014), and could also be converted into nano-arsenic compounds for cancer treatment (Ahn et al., 2010). EDX elemental analysis of the As nanoparticles shows that there are some impurities of sodium (6.4\%) and sulphur $(1.3 \%)$ on the particles. These impurities are believed to be from the L-cysteine $\left(\mathrm{C}_{3} \mathrm{H}_{7} \mathrm{NO}_{2} \mathrm{~S}\right)$ used for pre-treatment, and the $\mathrm{NaBH}_{4}$ reducing agent.

\section{Conclusion}

Strategies for integrated phytoremediation of soil contaminated with arsenic and extractions of commercially valuable products have been investigated in this study. Pteris cretica ferns species were used as the phyto-accumulators in the uptake of arsenic from soil contaminated with $200 \pm 3 \mathrm{mg} \mathrm{kg}^{-1}$ of arsenic in the form of As(V). The Pteris cretica ferns were shown to be capable of hyperaccumulation of arsenics, with maximum accumulations of about $4427 \pm 79 \mathrm{mg} \mathrm{kg}^{-1}$ to $4875 \pm 96 \mathrm{mg}$ $\mathrm{kg}^{-1}$ of arsenic per kg of the dry ferns after $30 \mathrm{~d}$. The arsenic in the Pteris cretica fronds was extracted into various solvents, with extraction efficiencies of $94.3 \pm 2.1 \%$ for ethanol-water $(1: 1 \mathrm{v} / \mathrm{v}), 81.5 \pm$ $3.2 \%$ for $1: 1(\mathrm{v} / \mathrm{v})$ methanol-water, and $70.8 \pm 2.9 \%$ for water alone. The recovery efficiency of arsenic using a molybdic acid complex process was $90.8 \pm 5.3 \%$. The process was also able to recover phosphorus at $95.1 \pm 4.6 \%$. About $96 \pm 7.2 \%$ of the arsenic and $94 \pm 3.4 \%$ of the phosphorus extracted in the molybdic acid process were recovered as $\mathrm{Mg}_{3}\left(\mathrm{AsO}_{4}\right)_{2}$ and $\mathrm{Mg}_{3}\left(\mathrm{PO}_{4}\right)_{2}$, respectively. Arsenic nanoparticles of $45.5 \pm 11.3 \mathrm{~nm}$ average particle diameter were produced from the $\mathrm{Mg}_{3}\left(\mathrm{AsO}_{4}\right)_{2}$ obtained from the biomass through a two-stage reduction process- a pre-reduction of As(V) to As(III) with L-cysteine, followed by $\mathrm{NaBH}_{4}$ reduction of the As(III) to As(0). The arsenic nanoparticles 
obtained are potentially valuable in treatment of Leishmania donovani infections and, can be converted

to other forms of arsenic for treatment of some types of cancer, while the $\mathrm{Mg}_{3}\left(\mathrm{AsO}_{4}\right)_{2}$ could be

converted to more valuable forms of arsenic such as arsenic nanoparticles, arsenic trioxide for cancer

treatment, and gallium arsenide for electronic applications, or used as a pesticide. Phosphorus contents

of the Pteris cretica biomass was extracted as phosphomolybdic acid complex and converted to

$\mathrm{Mg}_{3}\left(\mathrm{PO}_{4}\right)_{2}$, which could be useful as a soil fertiliser. Recovery of these valuable products from biomass used in phytoremediation of arsenic-contaminated soil could incentivise and drive commercial industries' participation in remediation of contaminated lands.

\section{Acknowledgements}

The authors would like to thank Christina-Kathleen P. McSweeney for her help with the Pteris cretica cultivation and total arsenic quantification at the early stage of this study. This work was supported by the UK Engineering and Physical Sciences Research Council (EPSRC) through grant number EP/K026216/1 (Cleaning Land for Wealth).

\section{$474 \quad$ References}

Afifi, M.M.I., Estefanous, A.N., El-Akshar, Y.S., 2012. Biological, chemical and physical properties of organic wastes as indicators maturation of compost. J. Appl. Sci. Res. 8, 1857-1869.

Ahn, R.W., Chen, F., Chen, H., Stern, S.T., Clogston, J.D., Patri, A.K., Raja, M.R., Swindell, E.P., Parimi, V., Cryns, V.L., O'Halloran, T.V., 2010. A novel nanoparticulate formulation of arsenic trioxide with enhanced therapeutic efficacy in a murine model of breast cancer. Clin. Cancer Res. 16, 3607-3617.

Anderson, C.W.N., Brooks, R.R., Chiarucci, A., Lacoste, C.J., Leblanc, M., Robinson, B.H., Simcock, R., Stewart, R.B., 1999. Phytomining for nickel, thallium and gold. J. Geochem. Explor. 67, 407-415.

Asante, K.A., Agusa, T., Subramanian, A., Ansa-Asare, O.D., Biney, C.A., Tanabe, S., 2007. Contamination status of arsenic and other trace elements in drinking water and residents from Tarkwa, a historic mining township in Ghana. Chemosphere 66, 1513-1522.

Baláž, P., Sedlák, J., 2010. Arsenic in cancer treatment: challenges for application of realgar nanoparticles (a minireview). Toxins 2, 1568-1581.

Cai, Y., Georgiadis, M., Fourqurean, J.W., 2000. Determination of arsenic in seagrass using inductively coupled plasma mass spectrometry. Spectrochim. Acta B 55, 1411-1422. 
Chakraborty, S., Bhar, K., Saha, S., Chakrabarti, R., Pal, A., Siddhanta, A., 2014. Novel arsenic nanoparticles are more effective and less toxic than As (III) to inhibit extracellular and intracellular proliferation of Leishmania donovani. J.Parasitol. Res. 2014, 10.

Chen, W.T., Tsai, L.C., Tsai, F.-C., Shu, C.-M., 2012. Recovery of gallium and arsenic from gallium arsenide waste in the electronics industry. CLEAN - Soil, Air, Water 40, 531-537.

Costa, B.E.S., Coelho, L.M., Araujo, C.S.T., Rezende, H.C., Coelho, N.M.M., 2016. Analytical strategies for the determination of arsenic in rice. J. Chem. 2016, 1-11.

Defra, 2014. SP1011 Final project report: examination of contaminated land sector activity in England. http://sciencesearch.defra.gov.uk/Default.aspx?Menu=Menu\&Module=More\&Location=None\&Co mpleted=0\&ProjectID=136. Accessed on $20^{\text {th }}$ December, 2017.

Devi, L., Ptasinski, K.J., Janssen, F.J.J.G., 2003. A review of the primary measures for tar elimination in biomass gasification processes. Biomass Bioenergy 24, 125-140.

Drake, T., Keating, M., Summers, R., Yochikawa, A., Pitman, T., Dodd, A.N., 2016. The cultivation of Arabidopsis for experimental research using commercially available peat-based and peat-free growing media. PLoS ONE 11, 10.1371/journal.pone.0153625.

Ha, N.T.H., Sakakibara, M., Sano, S., Nhuan, M.T., 2011. Uptake of metals and metalloids by plants growing in a lead-zinc mine area, Northern Vietnam. J. Hazard. Mater. 186, 1384-1391.

Hamiti, N., Jaffrezic-Renault, N., Revel, G., Poitrenaud, C., 1985. Study of the extraction of phosphomolybdic acid by radiotracers and application to the titration of phosphorus in steels. J. Radioanal. Nucl. Chem. 90, 77-89.

Han, Y.H., Liu, X., Rathinasabapathi, B., Li, H.B., Chen, Y., Ma, L.Q., 2017. Mechanisms of efficient As solubilization in soils and As accumulation by As-hyperaccumulator Pteris vittata. Environ. Pollut. 227, 569-577.

Jankong, P., Visoottiviseth, P., Khokiattiwong, S., 2007. Enhanced phytoremediation of arsenic contaminated land. Chemosphere 68, 1906-1912.

Jiang, Y., Lei, M., Duan, L., Longhurst, P., 2015. Integrating phytoremediation with biomass valorisation and critical element recovery: A UK contaminated land perspective. Biomass Bioenergy 83, 328-339.

Komar, K.M., Ma, L.Q., Rockwood, D. and Syed, A, 1998. Identification of arsenic tolerant and hyperaccumulating plants from arsenic contaminated soils in Florida. Agronomy Abstract, p. 343.

Kumar, P.B.A.N., Dushenkov, V., Motto, H., Raskin, I., 1995. Phytoextraction: the use of plants to remove heavy metals from soils. Environ. Sci. Technol. 29, 1232-1238.

Larios, R., Fernández-Martínez, R., LeHecho, I., Rucandio, I., 2012. A methodological approach to evaluate arsenic speciation and bioaccumulation in different plant species from two highly polluted mining areas. Sci. Total Environ. 414, 600-607.

Li, S.-D., Huang, L., 2008. Pharmacokinetics and biodistribution of nanoparticles. Mol. Pharm. 5, 496504. 
Lievens, C., Yperman, J., Vangronsveld, J., Carleer, R., 2008. Study of the potential valorisation of heavy metal contaminated biomass via phytoremediation by fast pyrolysis: Part I. Influence of temperature, biomass species and solid heat carrier on the behaviour of heavy metals. Fuel 87, 1894 1905.

Liu, N., Jørgensen, U., Lærke, P.E., 2013. Quality determination of biomass for combustion: a new high-throughput microwave digestion method prior to elemental analysis by inductively coupled plasma-optical emission spectroscopy. Energy Fuels 27, 7485-7488.

Lu, D.P., Qiu, J.Y., Jiang, B., Wang, Q., Liu, K.Y., Liu, Y.R., Chen, S.S., 2002. Tetra-arsenic tetrasulfide for the treatment of acute promyelocytic leukemia: a pilot report. Blood 99, 3136-3143.

Ma, L.Q., Komar, K.M., Tu, C., Zhang, W., Cai, Y., Kennelley, E.D., 2001. A fern that hyperaccumulates arsenic. Nature 409, 579-579.

Maeda, H., Hori, S., Ohizumi, H., Segawa, T., Kakehi, Y., Ogawa, O., Kakizuka, A., 2004. Effective treatment of advanced solid tumors by the combination of arsenic trioxide and L-buthioninesulfoximine. Cell Death Differ. 11, 737-746.

Meharg, A.A., 2003. Variation in arsenic accumulation - hyperaccumulation in ferns and their allies. New Phytol. 157, 25-31.

Mukherjee, A., Sengupta, M.K., Hossain, M.A., Ahamed, S., Das, B., Nayak, B., Lodh, D., Rahman, M.M., Chakraborti, D., 2006. Arsenic contamination in groundwater: A global perspective with emphasis on the Asian scenario. J. Health Popul. Nutr. 24, 142-163.

National Research, C., 1999. Arsenic in Drinking Water. The National Academies Press, Washington, DC.

Nicolli, H.B., Suriano, J.M., Gomez Peral, M.A., Ferpozzi, L.H., Baleani, O.A., 1989. Groundwater contamination with arsenic and other trace elements in an area of the pampa, province of Córdoba, Argentina. Environ. Geol Water Sci. 14, 3-16.

Nzihou, A., Stanmore, B., 2013. The fate of heavy metals during combustion and gasification of contaminated biomass - a brief review. J. Hazard. Mater. 256-257, 56-66.

Pal, A., Saha, S., Maji, S.K., Kundu, M., Kundu, A., 2012. Wet-chemical synthesis of spherical arsenic nanoparticles by a simple reduction method and its characterization. Advanced Materials Letters 3, 177-180.

Park, Y.Y., Tran, T., Lee, Y.H., Nam, Y.I., Senanayake, G., Kim, M.J., 2010. Selective removal of arsenic $(\mathrm{V})$ from a molybdate plant liquor by precipitation of magnesium arsenate. Hydrometallurgy 104, 290-297.

Paul, J., 1966. Simultaneous determination of phosphorus. arsenic and germanium and the separation of silicon and arsenic by solvent extraction. Anal. Chim. Acta 35, 200-205.

Pudasainee, D., Paur, H.-R., Fleck, S., Seifert, H., 2014. Trace metals emission in syngas from biomass gasification. Fuel Process. Technol. 120, 54-60.

Rahman, M.A., Reichman, S.M., De Filippis, L., Sany, S.B.T., Hasegawa, H., 2016. Phytoremediation of toxic metals in soils and wetlands: concepts and applications. in: Hiroshi Hasegawa et al (Eds.). 
Environmental Remediation Technologies for Metal-Contaminated Soils, Springer, Tokyo, Japan, 161-195.

Reeves, R.D., Baker, A.J.M., 2000. Phytoremediation of toxic metals: using plants to clean up the environment. in: Raskin, I., Ensley, B.D. (Eds.). Metal-accumulating plants, John Wiley and Sons Inc., New York, 193-229.

Sas-Nowosielska, A., Kucharski, R., Małkowski, E., Pogrzeba, M., Kuperberg, J.M., Kryński, K., 2004. Phytoextraction crop disposal—an unsolved problem. Environ. Pollut. 128, 373-379.

Schneider, J., Stürmer, S.L., Guilherme, L.R.G., de Souza Moreira, F.M., Soares, C.R., 2013. Arbuscular mycorrhizal fungi in arsenic-contaminated areas in Brazil. J. Hazard. Mater. 262, 11051115

Sheikh, F.A., Barakat, N.A.M., Kanjwal, M.A., Park, S.J., Kim, H., Kim, H.Y., 2010. Gallium arsenide (GaAs) nanofibers by electrospinning technique as future energy server materials. Fiber Polym. 11, 384-390.

Shraim, A., Chiswell, B., Olszowy, H., 2000. Use of perchloric acid as a reaction medium for speciation of arsenic by hydride generation-atomic absorption spectrometry. Analyst 125, 949-953.

Srivastava, M., Ma, L.Q., Santos, J.A.G., 2006. Three new arsenic hyperaccumulating ferns. Sci. Total Environ. 364, 24-31.

Su, Y.H., McGrath, S.P., Zhu, Y.G., Zhao, F.J., 2008. Highly efficient xylem transport of arsenite in the arsenic hyperaccumulator Pteris vittata. New Phytol. 180, 434-441.

van der Ent, A., Baker, A.J.M., Reeves, R.D., Chaney, R.L., Anderson, C.W.N., Meech, J.A., Erskine, P.D., Simonnot, M.-O., Vaughan, J., Morel, J.L., Echevarria, G., Fogliani, B., Rongliang, Q., Mulligan, D.R., 2015. Agromining: farming for Metals in the Future? Environ. Sci. Technol. 49, 4773-4780.

Vervaeke, P., Tack, F.M.G., Navez, F., Martin, J., Verloo, M.G., Lust, N., 2006. Fate of heavy metals during fixed bed downdraft gasification of willow wood harvested from contaminated sites. Biomass Bioenergy 30, 58-65.

Wang, S., Mulligan, C.N., 2006. Occurrence of arsenic contamination in Canada: sources, behavior and distribution. Sci. Total Environ. 366, 701-721.

Waxman, S., Anderson, K.C., 2001. History of the development of arsenic derivatives in cancer therapy. Oncologist 6, 3-10.

Wei, C.Y., Chen, T.B., 2006. Arsenic accumulation by two brake ferns growing on an arsenic mine and their potential in phytoremediation. Chemosphere 63, 1048-1053.

Zhang, W., Cai, Y., Tu, C., Ma, L.Q., 2002. Arsenic speciation and distribution in an arsenic hyperaccumulating plant. Sci. Total Environ. 300, 167-177.

Zhao, D., Li, H.B., Xu, J.Y., Luo, J., Ma, L.Q., 2015. Arsenic extraction and speciation in plants: Method comparison and development. Sci. Total Environ. 523, 138-145.

Zhao, F.J., Dunham, S.J., McGrath, S.P., 2002. Arsenic hyperaccumulation by different fern species. New Phytol. 156, 27-31. 
602 Zhao, Y., Chen, J., 1996. Extraction of phosphorus, arsenic and/or silica from sodium tungstate and 603 molybdate solutions with primary amine and tributyl phosphate as solvents. I - synergistic extraction 604 and separation of phosphorus, arsenic and/or silica from tungstate and molybdate solutions. 605 Hydrometallurgy 42, 313-324.

606 